\title{
Prevalence and clinical correlates of bronchoreversibility in severe emphysema
}

\author{
M.K. Han*, R. Wise ${ }^{\#}$, J. Mumford ${ }^{\ddagger}$, F. Sciurba ${ }^{+}$, G.J. Criner ${ }^{\S}$, J.L. Curtis*, S. Murray ${ }^{f}$, \\ A. Sternberg ${ }^{\#}$, G. Weinman**, E. Kazerooni ${ }^{\# \#, ~ A . P . ~ F i s h m a n ~}{ }^{\pi}$, B. Make ${ }^{++}$, \\ E.A. Hoffman ${ }^{\S \S}$, Z. Mosenifar ${ }^{f f}$ and F.J. Martinez* for the NETT Research Group ${ }^{* \star *}$
}

ABSTRACT: Chronic obstructive pulmonary disease (COPD) exhibits airflow obstruction that is not fully reversible. The importance of bronchoreversibility remains controversial.

We hypothesised that an emphysematous phenotype of COPD would be associated with decreased bronchoreversibility.

544 patients randomised to the medical arm of the National Emphysema Treatment Trial formed the study group. Participants underwent multiple measurements of bronchoreversibility on a mean of four sessions over $1.91 \mathrm{yrs}$. They were also characterised by measures of symptoms, quality of life and quantitative measures of emphysema by computed tomography.

Mean baseline forced expiratory volume in $1 \mathrm{~s}\left(\mathrm{FEV}_{1}\right)$ in this patient population is $24 \%$ predicted. $22.2 \%$ of patients demonstrated bronchoreversibility on one or more occasions using American Thoracic Society/European Respiratory Society criteria. Few patients $(0.37 \%)$ had bronchoreversibility on all completed tests. Patients who demonstrated bronchoreversibility were more likely to be male, and have better lung function and less emphysema. $64 \%$ of patients demonstrated large $(\geqslant 400 \mathrm{~mL}$ ) changes in forced vital capacity (FVC).

In a severe emphysema population, bronchoreversibility as defined by change in FEV 1 is infrequent, varies over time, and is more common in males and those with less severe emphysema. Improvements in FVC, however, were demonstrated in the majority of patients.

KEYWORDS: Bronchodilator, chronic obstructive pulmonary disease, computed tomography, emphysema

$\mathrm{W}$ ith the recent demonstration that lung volume reduction therapy benefits selected patients with severe emphysema [1], accurate diagnosis and staging of patients with chronic obstructive pulmonary disease (COPD) assumes a new importance. In such clinical evaluations, however, it is uncertain how much weight should be accorded to physiological data versus imaging modalities. In particular, the role of bronchoreversibility in excluding asthma and defining varying clinical phenotypes in COPD patients remains controversial [2]. COPD has been characterised as a disorder with airflow obstruction that is not fully reversible [3, 4], but bronchoreversibility has been confirmed in a substantial proportion of patients clinically diagnosed with nonasthmatic COPD [5-7]. However, some studies have shown acute bronchodilator responses in small proportions of patients, similar to a normal population [8] but in contrast to the findings of others [9]. Careful prospective analyses are needed to define the relationships between diagnostic and staging modalities, and to avoid arbitrary patient classification. Given the limited data on the presence of bronchoreversibility in patients with emphysema [10-12], we examined bronchoreversibility in patients with computed tomography (CT)-defined emphysema randomised to the medical arm of the National Emphysema Treatment Trial (NETT). We hypothesised that patients with emphysema would rarely demonstrate bronchoreversibility and that greater emphysema volume, as quantified by $\mathrm{CT}$, would be associated with decreased bronchoreversibility.

For editorial comments see page 952.

This article has supplementary material available from www.erj.ersjournals.com

Earn CME accreditation by answering questions about this article. You will find these at the back of the printed copy of this issue or online at www.erj.ersjournals.com/misc/cmeinfo.dtl

AFFILIATIONS

*Division of Pulmonary and Critical Care,

\#\# Dept of Radiology, University of Michigan Health System,

${ }^{f}$ Dept of Biostatistics, University of Michigan School of Public Health, Ann Arbor, MI,

\# Dept of Epidemiology and Dept of Medicine, Johns Hopkins University, Baltimore,

**Division of Lung Diseases,

National Heart, Lung and Blood Institute, Bethesda, MD,

'Dept of Psychology, University of California,

${ }^{f}$ Division of Pulmonary Medicine, Cedars-Sinai Medical Center, Los Angeles, CA,

+Division of Pulmonary and Critical Care Medicine, University of Pittsburgh, Pittsburgh,

${ }^{\S}$ Pulmonary and Critical Care Medicine, Temple University, "Division of Pulmonary and Critical Care Medicine, University of Pennsylvania, Philadelphia, PA, ${ }^{++}$Division of Pulmonary Sciences, National Jewish Health, Denver, CO, ${ }^{\S}$ Dept of Radiology, University of lowa, lowa City, IA, USA.

***For a list of NETT Research Group members, please refer to the Acknowledgements section.

CORRESPONDENCE

M.K. Han, Division of Pulmonary and Critical Care Medicine, 3916

Taubman Center, Box 0360, 1500 E. Medical Center Drive, University of Michigan Medical Center, Ann Arbor, MI 48109-0360, USA

E-mail: mrking@umich.edu

Received:

March 312009

Accepted after revision:

Oct 202009

First published online:

Nov 192009

European Respiratory Journal

Print ISSN 0903-1936

Online ISSN 1399-3003 


\section{METHODS}

\section{Patient selection}

The study group of 544 patients includes patients randomised to medical therapy at 17 clinics as part of the NETT and in whom quantitative measurement of emphysema volume and distribution was available (see below). The design and methods of the trial have been previously detailed [13]. Major enrolment criteria include bilateral emphysema evaluated by chest CT and determined to be suitable for lung volume reduction, forced expiratory volume in $1 \mathrm{~s}$ (FEV1) $\leqslant 45 \%$ predicted, total lung capacity (TLC) $\geqslant 100 \%$ pred, residual volume $\geqslant 150 \%$ pred and arterial carbon dioxide tension $\leqslant 60 \mathrm{mmHg}$ (55 $\mathrm{mmHg}$ in Denver, CO, USA). All patients had to be validated nonsmokers for $\geqslant 4$ months prior to screening and be free of any important comorbidity. All patients provided written informed consent, and the study was approved by the institutional review board at each clinic.

\section{Clinical assessment}

Demographic data and medical history were collected by patient interview using standardised instruments.

\section{Physiological testing}

Patients underwent spirometry before and after two inhalations of albuterol (total of $116 \mu \mathrm{g}$ ) via metered-dose inhaler, while plethysmographic lung volumes and diffusing capacity of the lung for carbon monoxide $(D \mathrm{~L}, \mathrm{CO})$ were measured 15 min after albuterol administration. Per protocol, bronchodilators were held for $4 \mathrm{~h}$ prior to pulmonary function testing. All spirometric manoeuvres met or exceeded American Thoracic Society (ATS)/European Respiratory Society (ERS) criteria for acceptability; the forced vital capacity (FVC) manoeuvres lasted or exceeded 6 s [14]. Arterial blood gases were also measured but at the discretion of the clinic staff with respect to bronchodilator administration. Spirometry, before and after albuterol administration, was repeated after pulmonary rehabilitation and then at $6,12,24,36,48$ and 60 months after randomisation. Inspiratory resistance measurements were available in 91 subjects as part of a substudy performed at four centres. Data on expiratory time was not recorded as part of the original dataset but was retrospectively collected on 100 randomly selected subjects as part of additional analyses for this manuscript.

\section{Diagnostic imaging studies}

Emphysema severity and distribution was determined from chest CT scans obtained at full inspiration. After segmenting and dividing the lung according to previously described protocols [15], images were analysed using custom-built software, the Pulmonary Analysis Software Suite. The density histogram was plotted, with values less than -950 HU corresponding to severe emphysema and regions with values of $-910 \mathrm{HU}$ and $-850 \mathrm{HU}$ roughly equating to moderate and mild emphysema, respectively. The alpha value (inverse slope) was determined from the log-log relationship of hole size versus number of holes [16]. Lungs with greater proportions of small lesions have a steep negative slope and a large alpha.

\section{Statistical analyses}

To define a positive response to albuterol, we performed analyses using criteria for bronchoreversibility based on ATS/
ERS joint guidelines, defined as an increase in FEV1 of $\geqslant 200 \mathrm{~mL}$ and $\geqslant 12 \%$ absolute value [17]. In addition, we examined the proportion of patients that experienced an absolute increase in FEV1 $\geqslant 400 \mathrm{~mL}$ [18] and those that experienced both $a \geqslant 400 \mathrm{~mL}$ increase in FVC and $\mathrm{a} \geqslant 12 \%$ rise in absolute FVC. Logistic regression analyses were used to evaluate the impact of demographic features, baseline pulmonary physiology, and quantity and distribution of emphysema on the presence of a positive response to albuterol. Unpaired t-tests were used to compare continuous measures between the groups who met the different criteria to those who never met the criteria. Chi-squared tests were used to compare bivariate measures across groups unless cell counts were less than five, in which case a Fisher's exact test was used. To assess whether a subject's ATS/ERS criteria at one time point agreed with their criteria at the next time point, kappa statistics were calculated. Finally, as this is an exploratory analysis, no adjustment for multiple comparisons was made. As such, it is possible by chance alone that one in 20 comparisons may be spuriously statistically significant.

\section{RESULTS}

544 patients randomised to medical therapy who had quantification of emphysema volume and distribution at baseline and pre- and post-bronchodilator FEV1 measured at the pre-rehabilitation visit formed the study group. These patients underwent a mean $\pm \mathrm{SD}$ of $4.16 \pm 1.58$ spirometric bronchoreversibility studies over the course of their participation in NETT $(1.85 \pm 1.30$ yrs from the first bronchoreversibility study to the last). Table 1 provides descriptive characteristics of the study group at the pre-rehabilitation evaluation (more extensive characterisation is available in online depository table E1). In general, the cohort was characterised by severe airflow obstruction and moderately severe emphysema.

Table 2 enumerates the proportion of patients at each time point who met the ATS/ERS criteria for bronchoreversibility

\begin{tabular}{|c|c|c|}
\hline \multicolumn{2}{|c|}{ Males/females $n$} & $345 / 199$ \\
\hline \multicolumn{2}{|c|}{ Smoking history pack-yrs } & $66.1 \pm 31.8$ \\
\hline \multicolumn{2}{|l|}{ Age yrs } & $66.4 \pm 6.0$ \\
\hline \multicolumn{2}{|l|}{$\mathrm{BMI} \mathbf{k g} \cdot \mathrm{m}^{-2}$} & $24.9 \pm 3.7$ \\
\hline \multicolumn{2}{|c|}{ Pre-bronchodilator FEV $1 \%$ pred } & $24.0 \pm 6.7$ \\
\hline \multicolumn{2}{|c|}{ Pre-bronchodilator FVC \% pred } & $58.1 \pm 15.2$ \\
\hline \multicolumn{2}{|l|}{ TLC \% pred } & $129.0 \pm 13.8$ \\
\hline \multicolumn{2}{|l|}{ RV \% pred } & $224.5 \pm 47.1$ \\
\hline \multicolumn{2}{|c|}{ DL,CO \% pred } & $28.6 \pm 9.9$ \\
\hline \multicolumn{2}{|c|}{ Post-bronchodilator FEV 1 change $\mathrm{mL}$} & $94.6 \pm 84.5$ \\
\hline \multicolumn{2}{|c|}{$\mathrm{FEV}_{1 / \mathrm{FVC}}$ ratio $\%$} & $31.4 \pm 6.2$ \\
\hline \multicolumn{2}{|c|}{ Whole lung emphysema \% (-950 HU) } & $15.9 \pm 10.5$ \\
\hline
\end{tabular}

Data are presented as mean $\pm \mathrm{SD}$, unless otherwise stated. BMI: body mass index; FEV1: forced expiratory volume in $1 \mathrm{~s} ; \%$ pred: \% predicted; FVC: forced vital capacity; TLC: total lung capacity; RV: residual volume; DL,CO: diffusing capacity of the lung for carbon monoxide. See table E1 in online depository for more detailed baseline patient characteristic information. 
and the mean FEV1 at each time point. 542 underwent repeat bronchoreversibility testing after pulmonary rehabilitation, 393 at 6 months, 328 at 12 months, 255 at 24 months, 137 at 36 months, 31 at 48 months and 20 at 60 months after randomisation. Figure 1 illustrates the number of patients that met ATS/ERS bronchoreversibility criteria during the first 2 yrs of follow-up. It is evident that a similar proportion of patients met these criteria at each time point of follow-up after randomisation (approximately $\leqslant 10 \%$; fig. 1). Importantly, the baseline pre-bronchodilator FEV1 was similar at each time point. Kappa statistics were used to check if a patient's ATS/ ERS criteria at one time point agreed with their criteria at the next time point, with a high kappa (closer to 1) indicating good agreement between time points. In all but one case, the absolute value of the kappa statistic was $<0.4$, indicating agreement between ATS/ERS criteria from one time point to another was most likely due to chance. In one case, a kappa of 1 was achieved (between the 36 and 48 month visits), but there was a small sample size for this group $(n=26)$.

Similar results are enumerated in table 3 utilising varying definitions for bronchoreversibility. For example, 121 out of $544(22.2 \%)$ patients met the ATS/ERS bronchoreversibility criteria at least once during multiple tests. Importantly, only two out of $544(0.4 \%)$ patients met this criterion during every testing period. Using a larger absolute change in FEV1 $(\geqslant 400 \mathrm{~mL}$ increase) identified a smaller proportion of patients that exhibited such a level of bronchoreversibility at least once (10 out of 544; $1.8 \%$ ). A $400 \mathrm{~mL}$ and $12 \%$ increase in FVC was seen in a larger proportion of patients at least once (348 out of $544 ; 64 \%$ ); 45 patients met this criterion during each testing period.

We next examined differences between varying clinical, physiological and imaging characteristics between those patients that met the various bronchoreversibility criteria at least once versus those that did not (tables 4 and 5; more detailed information available in online depository tables E4 and E5). Interestingly, proportionately fewer females (10.6\%) met the ATS/ERS reversibility criteria compared to males (29.0\%). Similarly, patients who met reversibility criteria generally exhibited less severe physiological impairment evidenced by a higher FEV1, FVC, DL,CO and 6-min walk distance and lower TLC. No consistent difference was seen in health status, symptoms or emphysema percentage.

Table 6 provides multivariate models examining various factors that influenced the likelihood of meeting the differing bronchoreversibility criteria. In general, males and patients with higher FEV1 were more likely to exhibit bronchoreversibility, while patients with lower per cent emphysema were less likely to demonstrate bronchoreversibility on one or more test sessions. Data on inspiratory lung resistance were available in 91 patients. Among these, in patients who met ATS/ ERS criteria for bronchoreversibility as compared to those who did not (21 versus 70), mean inspiratory resistance at baseline visit was 3.9 versus $7.0 \mathrm{cmH}_{2} \mathrm{O} \cdot \mathrm{L}^{-1} \cdot \mathrm{s}^{-1}(\mathrm{p}=0.0006)$. In patients who met FVC bronchoreversibility criteria versus those who did not (58 versus 33), the mean inspiratory resistance was 5.3 versus $8.1 \mathrm{cmH}_{2} \mathrm{O} \cdot \mathrm{L}^{-1} \cdot \mathrm{s}^{-1} \quad(\mathrm{p}=0.0004)$. Thus those who met bronchoreversibility criteria actually had lower inspiratory resistance than those who did not meet bronchoreversibility criteria. We also repeated the multivariate analysis in table 6 predicting likelihood of meeting bronchoreversibility FVC criteria including inspiratory resistance in the model. No predictors met statistical significance with the smaller sample size but a trend toward decreased likelihood of bronchoreversibility with increasing inspiratory resistance was seen (data not shown). The mean pre-bronchodilator expiratory time was $15.2 \mathrm{~s}$ and the mean post-bronchodilator expiratory time was $16.1 \mathrm{~s}$ in 100 randomly selected subjects $(\mathrm{p} \leqslant 0.0001)$. However, the correlation between change in expiratory time after bronchodilator and improvement in FVC after bronchodilator was weak $(r=0.31)$. The coefficient of determination suggests that $9 \%$ of the variability in change in FVC is predicted by change in expiratory time.

\section{DISCUSSION}

In this large group of carefully characterised, prospectively studied patients with severe emphysema, we show: 1) that among patients selected for surgical therapy of severe emphysema, bronchoreversibility meeting ATS/ERS criteria exists in a small subgroup; 2) while the proportion of patients

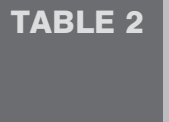
that that met or did not meet American Thoracic Society (ATS)/European Respiratory Society (ERS) criteria for bronchoreversibility and the mean forced expiratory volume in $1 \mathrm{~s}$ (FEV1) at each time point

\begin{tabular}{lcccc} 
Time point & Total $\mathbf{n}$ & $\begin{array}{c}\text { Did not meet } \\
\text { ATS/ERS BR criteria }\end{array}$ & $\begin{array}{c}\text { Met ATS/ERS } \\
\text { BR criteria }\end{array}$ & $\begin{array}{c}\text { Pre-bronchodilator } \\
\text { mean FEV } \mathbf{~ L ~}\end{array}$ \\
\hline Before rehabilitation & 544 & $488(89.7)$ & $56(10.3)$ & $0.70 \pm 0.22$ \\
After rehabilitation & 542 & $503(92.8)$ & $39(7.2)$ & $0.70 \pm 0.22$ \\
$\mathbf{6}$ months after randomisation & 393 & $355(90.3)$ & $38(9.7)$ & $0.70 \pm 0.24$ \\
$\mathbf{1 2}$ months after randomisation & 328 & $300(91.5)$ & $28(8.5)$ & $0.72 \pm 0.26$ \\
$\mathbf{2 4}$ months after randomisation & 255 & $235(92.2)$ & $20(7.8)$ & $0.73 \pm 0.29$ \\
$\mathbf{3 6}$ months after randomisation & 137 & $130(94.9)$ & $2(5.1)$ & $0.71 \pm 0.28$ \\
$\mathbf{4 8}$ months after randomisation & 31 & $29(93.6)$ & $0.5(0.0)$ & $0.76 \pm 0.28$ \\
$\mathbf{6 0}$ months after randomisation & 20 & $20(100.0)$ & $0.76 \pm 0.39$ \\
\hline
\end{tabular}

Data are presented as mean \pm SD or $n(\%)$, unless otherwise stated. BR: bronchodilator response. 


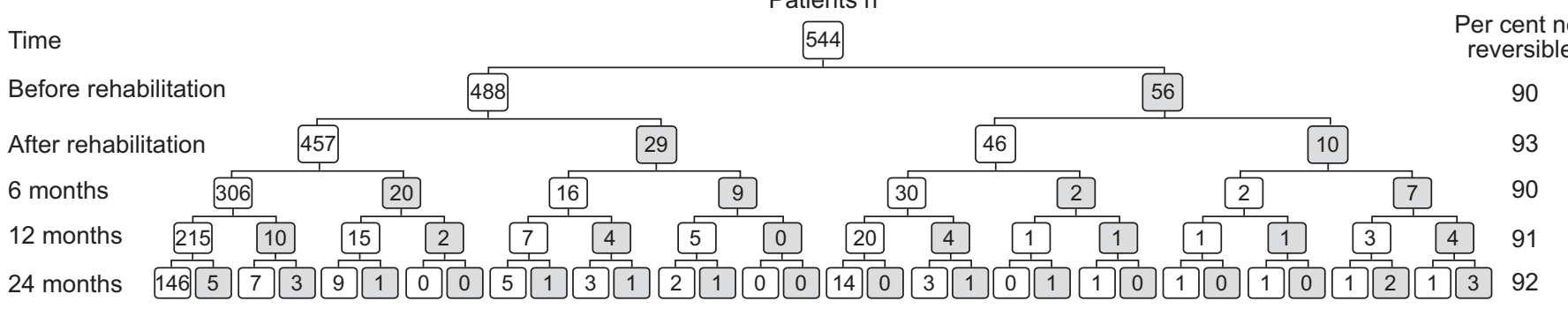

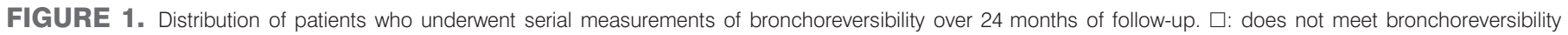
criterion; 1 : meets bronchoreversibility criterion.

meeting bronchoreversibility criteria varies by the physiological criteria utilised to define a positive response, the majority of patients exhibited large increase in FVC; 3) females are less likely to exhibit bronchoreversibility; and 4) the quantity of emphysema determined by high-resolution computed tomography (HRCT) is a negative predictor of meeting a volume, bronchoreversibility criterion. These data shed new light on the physiological characteristics of COPD patients with severe emphysema.

The finding that significant bronchoreversibility can be shown among patients with advanced emphysema is further evidence against the common belief that the airflow obstruction in severe COPD is largely irreversible. Our data qualitatively agree with the finding of bronchoreversibility in a significant number of patients in the ISOLDE (Inhaled Steroids in Obstructive Lung Disease) trial [5], and in several other recent studies of COPD patients [7, 19-21]. The overall percentage of patients meeting standard FEV1 criteria was lower than in these reports, but similar to the findings in the Lung Health Study, which included patients with mild to moderate airflow obstruction regardless of presence or absence of emphysema [8]. Our current data extend previous findings by examining various physiological thresholds during multiple tests in carefully characterised patients with advanced COPD and an emphysematous phenotype. As such, we demonstrate that the quantity of emphysema, assessed by $\mathrm{CT}$, impacts bronchoreversibility as defined by $12 \%$ change and $400 \mathrm{~mL}$ increase in FVC. Several possible explanations exist for the association between greater emphysema and lower likelihood of bronchoreversibility as defined by FVC criteria. The mechanical interdependence of the airways and airspaces may be such that bronchoreversibility is more difficult to elicit in patients with more severe emphysema. The amount of airway muscle could also be less in patients with more severe parenchymal destruction. A recently published analysis of radiographic data in the NETT suggests an inverse relationship between emphysema severity and airway wall thickness [22]; thus, less airways disease may be representative of this patient phenotype.

Although some have suggested that bronchoreversibility testing should be used to rule out a diagnosis of asthma in patients with suspected COPD [4], such testing appears to be of limited diagnostic value in this setting [23]. One reason is overlap between the definitions of asthma, an inflammatory condition with at least partially reversible obstruction and COPD (a condition with airflow limitation that is not fully reversible [4]. Indeed, a subset of COPD patients has even been shown to exhibit partial bronchoreversibility, increased exhaled nitric oxide and sputum eosinophilia, markers generally more closely associated with a diagnosis of asthma [24]. The Global Initiative for Obstructive Lung Disease criteria for COPD diagnosis do not require "lack" of reversibility, nor do they include a strict reversibility criterion for COPD. The words "not fully reversible" are included in the definition, but in the spirometric criteria, no mandatory limit to reversibility is required for COPD diagnosis. A second reason limiting the utility of bronchoreversibility testing in this setting is that the degree of bronchoreversibility in individual COPD patients is variable from day to day. Although the mean increase in FEV1 in 985 COPD patients in the Intermittent Positive Pressure Ventilation trial was $15 \%, 68 \%$ of the patients showed an increase in FEV1 from baseline of greater than 15\% at least once during seven follow-up tests over 2.5-3 yrs [6]. Collectively, these findings argue that the demonstration of bronchoreversibility not be taken to exclude the diagnosis of COPD.

TABLE 3 Number of patients (out of 544) meeting various spirometric bronchoreversibility criteria throughout the entire period of evaluation

\begin{tabular}{lccc} 
Criterion & $\begin{array}{c}\text { Patients meeting criterion } \\
\text { at least once }\end{array}$ & $\begin{array}{c}\text { Patients not meeting criterion } \\
\text { at least once }\end{array}$ & $\begin{array}{c}\text { Patients meeting specific } \\
\text { criterion at all visits }\end{array}$ \\
\hline ATS/ERS & $121(22.2)$ & $423(77.8)$ & 2 \\
FEV $1 \geqslant \mathbf{4 0 0 ~} \mathbf{~ L L}$ & $10(1.8)$ & $534(98.2)$ & 0 \\
FVC $\geqslant \mathbf{4 0 0} \mathbf{~ m L}$ and $\mathbf{1 2} \%$ increase & $348(64.0)$ & $196(36.0)$ & 45 \\
\hline
\end{tabular}

Data are presented as $n$ or $n(\%)$. ATS: American Thoracic Society; ERS: European Respiratory Society; FEV1: forced expiratory volume in 1 s; FVC: forced vital capacity 


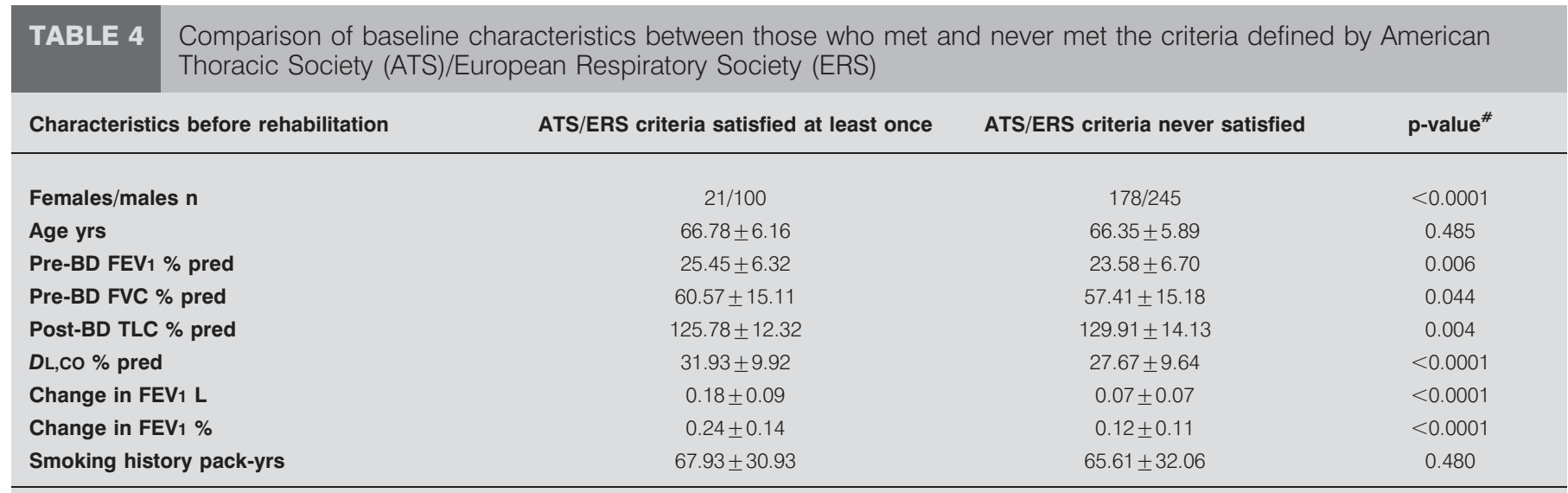

Data are presented as mean $\pm \mathrm{SD}$, unless otherwise stated. BD: bronchodilator; FEV1: forced expiratory volume in $1 \mathrm{~s}$; \% pred: \% predicted; FVC: forced vital capacity; TLC: total lung capacity; DL,CO: diffusing capacity of the lung for carbon monoxide. ${ }^{*}$ : calculated using an unpaired t-test, except categorical variables, which used a Chisquared test if cell counts were greater than five and a Fisher's exact test otherwise. More detailed comparisons available in online depository table E4.

A novel approach taken in this study is the assessment of changes in FVC as a marker of residual volume changes after bronchodilator administration in patients with severe emphysema. Theoretically, post-bronchodilator improvements in FVC could be attributed to true bronchodilator effect or "training" effect with patients learning to blow longer with each subsequent manoeuvre [25]. While we demonstrated that post-bronchodilator expiratory time was $\sim 1 \mathrm{~s}$ longer than prebronchodilator expiratory time, the difference in expiratory time accounts for only $9 \%$ of the variation in post-bronchodilator FVC change in these subjects.

Significant improvements in FVC after bronchodilator administration in subjects with emphysema were also reported by O'DONNELL et al. [10] who examined 84 patients with clinically diagnosed emphysema, $\sim 40 \%$ of whom had a $\geqslant 10 \%$ improvement in FVC after the administration of $200 \mu \mathrm{g}$ salbutamol. In our larger, longitudinal study focusing on a $12 \%$ and $400 \mathrm{~mL}$ increase in $\mathrm{FVC}$, a majority of patients $(64 \%)$ met this criterion at some point during testing with 45 out of $547(8.3 \%)$ patients exhibiting such a change at every test. The clinical relevance of these data should not be underestimated. The change in lung volume after a bronchodilator has become an important characteristic in recent studies [10, 26, 27]. This finding is clinically relevant because such a decrement in lung volume correlates best with improved breathlessness during exercise [28] and improvement in symptoms after therapeutic interventions $[29,30]$. While relatively fewer patients in our study demonstrated bronchoreversibility by FEV1 criteria than FVC criteria, it is possible that in this patient population improvements in FVC may be just as clinically meaningful if not more meaningful. Interestingly, data from UPLIFT (Understanding Potential Long-term Impacts on Function with Tiotropium) [7] demonstrated that the percentage of patients with an isolated FVC improvement as compared to FEV1 improvement increased with the severity of airflow obstruction. Thus, pharmacological lung reduction through bronchodilator therapy is both an important and obtainable goal in this patient population.

TABLE 5 Comparison of baseline characteristics between those who met and never met the criteria defined by forced expiratory volume in $1 \mathrm{~s}\left(F E V_{1}\right) \geqslant 400 \mathrm{~mL}$ and forced vital capacity $(F V C)>400 \mathrm{~mL}$ change

FVC $\geqslant 400 \mathrm{~mL}$ and $12 \%$ satisfied

FVC $\geqslant 400 \mathrm{~mL}$ and $12 \%$ never satisfied

p-value ${ }^{\#}$

$\begin{array}{lc}\text { Females/males } \mathbf{n} & 82 / 266 \\ \text { Age yrs } & 66.15 \pm 6.20 \\ \text { Pre-BD FEV } 1 \text { \% pred } & 23.29 \pm 6.28 \\ \text { Pre-BD FVC \% pred } & 57.05 \pm 14.80 \\ \text { Post-BD TLC \% pred } & 128.56 \pm 13.66 \\ \text { DL,Co \% pred } & 29.44 \pm 10.16 \\ \text { Change in FEV } 1 \text { L } & 0.12 \pm 0.08 \\ \text { Change in FEV } 1 \text { \% } & 0.18 \pm 0.13 \\ \text { Smoking history pack-yrs } & 69.41 \pm 33.22\end{array}$

Data are presented as mean $\pm \mathrm{SD}$, unless otherwise stated. BD: bronchodilator; \% pred: \% predicted; TLC: total lung capacity; $D \mathrm{~L}, \mathrm{CO}$ : diffusing capacity of the lung for carbon monoxide. ${ }^{\#}$ : calculated using an unpaired t-test, except categorical variables, which used a Chi-squared test if cell counts were greater than five and a Fisher's exact test otherwise. More detailed comparisons available in online depository table E5. 


\begin{tabular}{|c|c|c|c|}
\hline \multirow{2}{*}{$\begin{array}{l}\text { TABLE } 6 \\
\text { Predictor }\end{array}$} & \multicolumn{3}{|c|}{$\begin{array}{l}\text { Multivariate logistic models where the outcome } \\
\text { has a value of } 1 \text { if the patient ever met the } \\
\text { bronchoreversibility criterion }{ }^{\#}\end{array}$} \\
\hline & & OR $(95 \% \mathrm{Cl})$ & p-value \\
\hline \multicolumn{4}{|c|}{$\begin{array}{l}12 \% \text { change in FVC as well as a } 400 \mathrm{~mL} \\
\text { increase }\end{array}$} \\
\hline \multicolumn{2}{|c|}{$\begin{array}{l}10 \% \text { increase in whole lung emphysema } \\
(-950 \mathrm{HU})\end{array}$} & $0.80(0.67-0.96)$ & 0.01 \\
\hline \multicolumn{2}{|l|}{ Male sex } & $5.83(3.75-9.07)$ & $<0.0001$ \\
\hline \multicolumn{2}{|c|}{ Age (10-yr increase) } & $0.60(0.43-0.84)$ & 0.003 \\
\hline \multicolumn{2}{|c|}{$0.1-\mathrm{L}$ increase in absolute $\mathrm{FEV}_{1}$} & $0.99(0.90-1.09)$ & 0.87 \\
\hline \multicolumn{4}{|c|}{ ATS/ERS criteria } \\
\hline \multicolumn{2}{|c|}{$\begin{array}{l}10 \% \text { increase in whole lung emphysema } \\
(-950 \mathrm{HU})\end{array}$} & $0.88(0.72-1.08)$ & 0.23 \\
\hline \multicolumn{2}{|l|}{ Male sex } & $2.37(1.37-4.12)$ & 0.002 \\
\hline \multicolumn{2}{|c|}{ Age (10-yr increase) } & $0.96(0.67-1.37)$ & 0.81 \\
\hline \multicolumn{2}{|c|}{$0.1-\mathrm{L}$ increase in absolute $\mathrm{FEV}_{1}$} & $1.25(1.13-1.38)$ & $<0.0001$ \\
\hline
\end{tabular}

FVC: forced vital capacity; FEV1: forced expiratory volume in $1 \mathrm{~s}$; ATS: American Thoracic Society; ERS: European Respiratory Society. " $: n=544$.

A further interesting finding of our study was the relationship between sex and the likelihood of bronchoreversibility. The multivariate models in table 6 demonstrate male sex to be significantly associated with an increased likelihood of bronchoreversibility by both the ATS/ERS (OR 2.37, 95\% CI 1.37-4.12; $\mathrm{p}=0.002)$ and the increase in FVC by $12 \%$ and $400 \mathrm{~mL}$ (OR 5.83, 95\% CI 3.75-9.07; p<0.0001) criteria, after adjusting for the percentage of emphysema, age and FEV1. We know that the smaller airway calibre of females could make female participants more likely to demonstrate bronchoreversibility due to the fact that airflow resistance is inversely related to the fourth power of the radius. Thus, for the same degree of airway dilation, the less the initial airway radius, the greater the drop in resistance. By adjusting for FEV1, we should eliminate this sex effect [31]. Limited data are available with respect to the relationship between sex and bronchodilation in COPD. An unadjusted sex analysis of the TRISTAN (double blind, randomised study of salmeterol/fluticasone versus placebo) data revealed a nonsignificant trend toward a greater increase in per cent predicted FEV1 with bronchodilator for males as compared to females, 4.89 versus 4.42 respectively $(p=0.18)$ [32]. TASHKIN et al. [7] examined bronchodilator responsiveness in patients enrolled in UPLIFT (average FEV1 $39.3 \%$ ) [7]. In that study, males were also more likely to meet the $\geqslant 12 \%$ and $\geqslant 200 \mathrm{~mL} \mathrm{FEV1}$ increase threshold in multivariate logistic regression. However, females were more likely than males to demonstrate bronchodilator reversibility using the criteria of $\geqslant 15 \%$ improvement in FEV1 or a $\geqslant 10 \%$ absolute increase in per cent predicted FEV1. If the differences we report are real, such sex differences would not be surprising. We have previously reported on other phenotypic differences between males and females in the NETT patient population, including: 1) overall less severe emphysema in females with the difference from males most evident in the outer peel of the lung; and 2) thicker small airway walls relative to luminal perimeters in females [33].
Finally, we demonstrated that patients with greater fractional volume of emphysema, as quantified by helical CT, have a decreased likelihood of demonstrating bronchoreversibility defined by a spirometric volume criterion. This finding persisted even when the data were adjusted for severity of airflow obstruction by the FEV1. Similarly, after adjusting for baseline pulmonary function, the odds of meeting ATS/ERS criteria for bronchoreversibility decreased as the quantity of emphysema increased. Our data agree with and extend a previous analysis of bronchoreversibility in COPD patients in which the extent of emphysema was measured by decreased DL,CO [10] but are in contrast to the finding of similar overall bronchoreversibility independent of emphysema extent in a smaller cohort of COPD patients [34]. In our cohort, both DL,CO and per cent emphysema were significant predictors of bronchoreversibility in a univariate model. Importantly, however, in a multivariate model that included both variables, only the quantity of emphysema remained a significant predictor of bronchoreversibility. Thus, the quantity of emphysema is better than $D \mathrm{~L}, \mathrm{CO}$ for predicting the absence of bronchoreversibility. It might be argued that this increased diagnostic efficiency does not justify the expense and radiation exposure of HRCT.

The percentage rise in FEV1 after bronchodilator administration has precedent as an important phenotypic marker in COPD. Although some investigators have suggested that the percentage rise in FEV1 positively correlates with survival, this relationship has not been noted when the post-bronchodilator FEV1 was substituted for the pre-bronchodilator FEV1 [35]. This has been confirmed by others who noted that the degree of reversibility did not improve the ability to predict survival when the best FEV1 per cent predicted was included in the model [36]. Similarly, the ISOLDE and Lung Health Study data suggest that bronchoreversibility is not associated with subsequent decline in pulmonary function [37] or the number of exacerbations [5]. In contrast, in patients with $\alpha_{1}$-antitrypsin deficiency, bronchoreversibility was associated with a greater rate of decline in FEV1 [38]. Several other studies have also reported bronchoreversibility to be associated with a greater rate of decline in FEV1 in subjects with moderately to severely advanced COPD $[39,40]$. Our data expand these results by confirming a significant decrease in bronchoreversibility in patients with increasing emphysema quantified by helical CT. As such, these data support differing clinical phenotypes of obstructive lung disease as determined by quantitative measurement of emphysema using CT. It should also be noted that minimal spirometric change does not necessarily mean lack of functional improvement or lung volume change after bronchodilator, even in this severely emphysematous group of patients. Post-bronchodilator spirometric testing may not necessarily be best way to assess benefit from bronchodilator in patients with such severe disease.

Our study has several limitations. First, all subjects were referred for the evaluation of surgical therapy for COPD, making a bias towards more severe airflow obstruction and increasing emphysema likely. The likelihood of such a bias is supported by the low mean FEV1 and the high percentage of emphysema noted in our cohort. Secondly, we examined bronchodilator response to two inhalations of albuterol by metered-dose inhaler after $15 \mathrm{~min}$. Although recent data 
suggest that higher doses of inhaled bronchodilators may result in increased bronchodilation [41], the dose of albuterol chosen in our study simulates standard clinical practice [21, 42]. The latter two considerations imply that our data may be a minimal estimate of the degree of bronchoreversibility in this patient population. In light of the recently adopted ATS/ERS guidelines which allow for four inhalations of albuterol for bronchodilator testing [43], future studies may show greater prevalence of bronchoreversibility. Finally, some patients with COPD who do not respond to a $\beta$-agonist respond to an anticholinergic bronchodilator, which would also suggest our data may underestimate the true prevalence of bronchodilator responsiveness in this patient population. Additional studies evaluating patients with a broader range of obstruction and quantity of emphysema are needed to confirm our findings.

In summary, we confirm that spirometric bronchodilator response is seen in some patients with severe airflow obstruction and increased emphysema volume determined by CT. Furthermore, we document a significantly decreased likelihood of meeting ATS/ERS bronchoreversibility criteria for patients with increased emphysema volume determined by helical CT. Importantly, a majority of emphysema patients exhibit lung volume reversibility after the administration of a short-acting bronchodilator. These subjects tend to have more severe disease physiologically and anatomically and are more likely to be males. These data provide additional data regarding the physiological and radiological phenotype of patients with severe COPD.

\section{SUPPORT STATEMENT}

The National Emphysema Treatment Trial (NETT) was supported by contracts with the National Heart, Lung, and Blood Institute (N01HR76101， N01HR76102， N01HR76103， N01HR76104， N01HR76105, N01HR76106, N01HR76107, N01HR76108, N01HR76109, N01HR76110, N01HR76111， N01HR76112, N01HR76113, N01HR76114, N01HR76115, N01HR76116, N01HR76118, and N01HR76119; Bethesda, MD, USA), the Centers for Medicare and Medicaid Services (Baltimore, MD, USA; formerly the Health Care Financing Administration) and the Agency for Healthcare Research and Quality. This research was further supported by National Institutes of Health grants K24 HL04212, K23 HL68713, and RO-1 HL56309; by a General Electric Radiology Research Academic Fellowship; by a grant from General Electric Medical Systems, CT Division (Waukesha, WI, USA); and by Merit Review and a Research Enhancement Award Program funding from the Department of Veterans Affairs (Washington, DC, USA). J.L. Curtis is supported by funding from a Research Enhancement Award Program (REAP) from the Biomedical Laboratory Research and Development Service, Department of Veterans Affairs.

\section{STATEMENT OF INTEREST}

None declared.

\section{ACKNOWLEDGEMENTS}

Members of the NETT Research Group are as follows.

Office of the Chair of the Steering Committee, University of Pennsylvania, Philadelphia, PA, USA: A.P. Fishman (chair), B.A. Bozzarello and A. Al-Amin.

\section{Clinical centers}

Baylor College of Medicine, Houston, TX, USA: M. Katz (principal investigator), C. Wheeler (principal clinic coordinator), E. Baker, P. Barnard, P. Cagle, J. Carter, S. Chatziioannou, K. Conejo-Gonzales, K. Dubose, J. Haddad, D. Hicks, N. Kleiman, M. Milburn-Barnes,
C. Nguyen, M. Reardon, J. Reeves-Viets, S. Sax, A. Sharafkhaneh, O. Wilson, C. Young, R. Espada (principal investigator 1996-2002), R. Butanda (1999-2001), M. Ellisor (2002), P. Fox (1999-2001), K. Hale (1998-2000), E. Hood (1998-2000), A. Jahn (1998-2000), S. Jhingran (1998-2001), K. King (1998-1999), C. Miller III (1996-1999), I. Nizami (co-principal investigator 2000-2001), T. Officer (1998-2000), J. Ricketts (1998-2000), J. Rodarte (co-principal investigator 1996-2000), R. Teague (co-principal investigator 1999-2000) and K. Williams (1998-1999).

Brigham and Women's Hospital, Boston, MA, USA: J. Reilly (principal investigator), D. Sugarbaker (co-principal investigator), C. Fanning (principal clinic coordinator), S. Body, S. Duffy, V. Formanek, A. Fuhlbrigge, P. Hartigan, S. Hooper, A. Hunsaker, F. Jacobson, M. Moy, S. Peterson, R. Russell, D. Saunders and S. Swanson (co-principal investigator 1996-2001).

Cedars-Sinai Medical Center, Los Angeles, CA, USA: R. McKenna (principal investigator), Z. Mohsenifar (co-principal investigator), C. Geaga (principal clinic coordinator), M. Biring, S. Clark, J. Cutler, R. Frantz, P. Julien, M. Lewis, J. Minkoff-Rau, V. Yegyan and M. Joyner (1996-2002).

Cleveland Clinic Foundation, Cleveland, OH, USA: M. DeCamp (principal investigator), J. Stoller (co-principal investigator), Y. Meli (principal clinic coordinator), J. Apostolakis, D. Atwell, J. Chapman, P. DeVilliers, R. Dweik, E. Kraenzler, R. Lann, N. Kurokawa, S. Marlow, K. McCarthy, P. McCreight, A. Mehta, M. Meziane, O. Minai, M. Steiger, K. White, J. Maurer (principal investigator 1996-2001), T. Durr (2000-2001), C. Hearn (1998-2001), S. Lubell (1999-2000), P. O’Donovan (1998-2003) and R. Schilz (1998-2002).

Columbia University, New York, NY in consortium with Long Island Jewish Medical Center, New Hyde Park, NY, USA: M. Ginsburg (principal investigator), B. Thomashow (co-principal investigator), $\mathrm{P}$. Jellen (principal clinic coordinator), J. Austin, M. Bartels, Y. Berkmen, P. Berkoski (site coordinator, Long Island Jewish Medical Center), F. Brogan, A. Chong, G. DeMercado, A. DiMango, S. Do, B. Kachulis, A. Khan, B. Mets, M. O'Shea, G. Pearson, L. Rossoff, S. Scharf (coprincipal investigator 1998-2002), M. Shiau, P. Simonelli, K. Stavrolakes, D. Tsang, D. Vilotijevic, C. Yip, M. Mantinaos (19982001), K. McKeon (1998-1999) and J. Pfeffer (1997-2002).

Duke University Medical Center, Durham, NC, USA: N. MacIntyre (principal investigator), R.D. Davis (co-principal investigator), J. Howe (principal clinic coordinator), R.E. Coleman, R. Crouch, D. Greene, K. Grichnik, D. Harpole Jr, A. Krichman, B. Lawlor, H. McAdams, J. Plankeel, S. Rinaldo-Gallo, S. Shearer, J. Smith, M. Stafford-Smith, V. Tapson, M. Steele (1998-1999) and J. Norten (1998-1999).

Mayo Foundation, Rochester, MN, USA: J. Utz (principal investigator), C. Deschamps (co-principal investigator), K. Mieras (principal clinic coordinator), M. Abel, M. Allen, D. Andrist, G. Aughenbaugh, S. Bendel, E. Edell, M. Edgar, B. Edwards, B. Elliot, J. Garrett, D. Gillespie, J. Gurney, B. Hammel, K. Hanson, L. Hanson, G. Harms, J. Hart, T. Hartman, R. Hyatt, E. Jensen, N. Jenson, S. Kalra, P. Karsell, J. Lamb, D. Midthun, C. Mottram, S. Swensen, A-M. Sykes, K. Taylor, N. Torres, R. Hubmayr (1998-2000), D. Miller (1999-2002), S. Bartling (1998-2000) and K. Bradt (1998-2002).

National Jewish Medical and Research Center, Denver, CO, USA: B. Make (principal investigator), M. Pomerantz (co-principal investigator), M. Gilmartin (principal clinic coordinator), J. Canterbury, M. Carlos, P. Dibbern, E. Fernandez, L. Geyman, C. Hudson, D. Lynch, J. Newell, R. Quaife, J. Propst, C. Raymond, J. Whalen-Price, K. Winner, M. Zamora and R. Cherniack (principal investigator 1997-2000).

Ohio State University, Columbus, OH, USA: P. Diaz (principal investigator), P. Ross (co-principal investigator), T. Bees (principal 
clinic coordinator), J. Drake, C. Emery, M. Gerhardt, M. King, D. Rittinger and M. Rittinger.

Saint Louis University, Saint Louis, MO, USA: K. Naunheim (principal investigator), R. Gerber (co-principal investigator), J. Osterloh (principal clinic coordinator), S. Borosh, W. Chamberlain, S. Frese, A. Hibbit, M.E. Kleinhenz, G. Ruppel, C. Stolar, J. Willey, F. Alvarez (coprincipal investigator 1999-2002) and C. Keller (co-principal investigator 1996-2000).

Temple University, Philadelphia, PA, USA: G. Criner (principal investigator), S. Furukawa (co-principal investigator), A.M. Kuzma (principal clinic coordinator), R. Barnette, N. Brister, K. Carney, W. Chatila, F. Cordova, G. D’Alonzo, M. Keresztury, K. Kirsch, C. Kwak, K. Lautensack, M. Lorenzon, U. Martin, P. Rising, S. Schartel, J. Travaline, G. Vance, P. Boiselle (1997-2000) and G. O'Brien (19972000).

University of California, San Diego, San Diego, CA, USA: A. Ries (principal investigator), R. Kaplan (co-principal investigator), C. Ramirez (principal clinic coordinator), D. Frankville, P. Friedman, J. Harrell, J. Johnson, D. Kapelanski, D. Kupferberg, C. Larsen, T. Limberg, M. Magliocca, F.J. Papatheofanis, D. Sassi-Dambron and M. Weeks.

University of Maryland at Baltimore, Baltimore, MD in consortium with Johns Hopkins Hospital, Baltimore, MD, USA: M. Krasna (principal investigator), H. Fessler (co-principal investigator), I. Moskowitz (principal clinic coordinator), T. Gilbert, J. Orens, S. Scharf, D. Shade, S. Siegelman, K. Silver, C. Weir and C. White.

University of Michigan, Ann Arbor, MI, USA: F. Martinez (principal investigator), M. Iannettoni (co-principal investigator), C. Meldrum (principal clinic coordinator), W. Bria, K. Campbell, P. Christensen, K. Flaherty, S. Gay, P. Gill, P. Kazanjian, E. Kazerooni, V. Knieper, T. Ojo, L. Poole, L. Quint, P. Rysso, T. Sisson, M. True, B. Woodcock and L. Zaremba.

University of Pennsylvania, Philadelphia, PA, USA: L. Kaiser (principal investigator), J. Hansen-Flaschen (co-principal investigator), M.L. Dempsey (principal clinic coordinator), A. Alavi, T. Alcorn, S. Arcasoy, J. Aronchick, S. Aukberg, B. Benedict, S. Craemer, R. Daniele, J. Edelman, W. Gefter, L. Kotler-Klein, R. Kotloff, D. Lipson, W. Miller Jr, R. O'Connell, S. Opelman, H. Palevsky, W. Russell, H. Sheaffer, R. Simcox, S. Snedeker, J. Stone-Wynne, G. Tino, P. Wahl, J. Walter, P. Ward, D. Zisman, J. Mendez (1997-2001) and A. Wurster (1997-1999).

University of Pittsburgh, Pittsburgh, PA, USA: F. Sciurba (principal investigator), J. Luketich (co-principal investigator), C. Witt (principal clinic coordinator), G. Ayres, M. Donahoe, C. Fuhrman, R. Hoffman, J. Lacomis, J. Sexton, W. Slivka, D. Strollo, E. Sullivan, T. Simon, C. Wrona, G. Bauldoff (1997-2000), M. Brown (1997-2002), E. George (principal clinic coordinator 1997-2001), R. Keenan (co-principal investigator 1997-2000), T. Kopp (1997-1999) and L. Silfies (1997-2001).

University of Washington, Seattle, WA, USA: J. Benditt (principal investigator), D. Wood (co-principal investigator), M. Snyder (principal clinic coordinator), K. Anable, N. Battaglia, L. Boitano, A. Bowdle, L. Chan, C. Chwalik, B. Culver, T. Gillespy, D. Godwin, J. Hoffman, A. Ibrahim, D. Lockhart, S. Marglin, K. Martay, P. McDowell, D. Oxorn, L. Roessler, M. Toshima and S. Golden (1998-2000).

\section{Other participants}

Agency for Healthcare Research and Quality, Rockville, MD, USA: L. Bosco, Y-P. Chiang, C. Clancy and H. Handelsman.

Centers for Medicare and Medicaid Services, Baltimore, MD, USA: S.M. Berkowitz, T. Carino, J. Chin, J. Baldwin, K. McVearry, A. Norris, S. Shirey, C. Sikora and S. Sheingold (1997-2004).
Coordinating Center, The Johns Hopkins University, Baltimore, MD, USA: S. Piantadosi (principal investigator), J. Tonascia (co-principal investigator), P. Belt, A. Blackford, K. Collins, B. Collison, R. Colvin, J. Dodge, M. Donithan, V. Edmonds, G.L. Foster, J. Fuller, J. Harle, R. Jackson, S. Lee, C. Levine, H. Livingston, J. Meinert, J. Meyers, D. Nowakowski, K. Owens, S. Qi, M. Smith, B. Simon, P. Smith, A. Sternberg, M. Van Natta, L. Wilson and R. Wise.

Cost Effectiveness Subcommittee: R.M. Kaplan (chair), J. Sanford Schwartz (co-chair), Y-P. Chiang, M.C. Fahs, A.M. Fendrick, A.J. Moskowitz, D. Pathak, S. Ramsey, S. Sheingold, A.L. Shroyer, J. Wagner and R. Yusen.

Cost Effectiveness Data Center, Fred Hutchinson Cancer Research Center, Seattle, WA, USA: S. Ramsey (principal investigator), R. Etzioni, S. Sullivan, D. Wood, T. Schroeder, K. Kreizenbeck, K. Berry and N. Howlader.

CT Scan Image Storage and Analysis Center, University of Iowa, Iowa City, IA, USA: E. Hoffman (principal investigator), J. Cook-Granroth, A. Delsing, J. Guo, G. McLennan, B. Mullan, C. Piker, J. Reinhardt, B. Robinswood, J. Sieren and W. Stanford.

Data and Safety Monitoring Board: J.A. Waldhausen (chair), G. Bernard, D. DeMets, M. Ferguson, E. Hoover, R. Levine, D. Mahler, A.J. McSweeny, J. Wiener-Kronish, O.D. Williams and M. Younes.

Marketing Center, Temple University, Philadelphia, PA, USA: G. Criner (principal investigator) and C. Soltoff.

Project Office, National Heart, Lung, and Blood Institute, Bethesda, MD, USA: G. Weinmann (project officer), J. Deshler (contracting officer), D. Follmann, J. Kiley and M. Wu (1996-2001).

Other acknowledgements

A. Gelb, Lakewood Regional Medical Center, Lakewood, CA, USA.

\section{REFERENCES}

1 Fishman A, Martinez F, Naunheim K, et al. A randomized trial comparing lung-volume-reduction surgery with medical therapy for severe emphysema. N Engl J Med 2003; 348: 2059-2073.

2 Petty T. COPD: clinical phenotypes. Pulm Pharmacol Therapeut 2002; 15: 341-351.

3 Celli B, MacNee W, Agusti A, et al. Standards for the diagnosis and treatment of patients with COPD: a summary of the ATS/ERS position paper. Eur Respir J 2004; 23: 932-946.

4 Rabe KF, Hurd S, Anzueto A, et al. Global strategy for the diagnosis, management, and prevention of chronic obstructive pulmonary disease: GOLD executive summary. Am J Respir Crit Care Med 2007; 176: 532-555.

5 Calverley PM, Burge PS, Spencer S, et al. Bronchodilator reversibility testing in chronic obstructive pulmonary disease. Thorax 2003; 58: 659-664.

6 Anthonisen N, Wright E. Bronchodilator response in chronic obstructive pulmonary disease. Am Rev Respir Dis 1986; 133: 814819 .

7 Tashkin DP, Celli B, Decramer M, et al. Bronchodilator responsiveness in patients with COPD. Eur Respir J 2008; 31: 742-750.

8 Anthonisen N, Skeans M, Wise R, et al. The effects of a smoking cessation intervention on 14.5-year mortality. A randomized clinical trial. Ann Int Med 2005; 142: 233-239.

9 Terzano C, Petroianni A, Ricci A, et al. Combination therapy in COPD: different response of COPD stages and predictivity of functional parameters. Eur Rev Med Pharmacol Sci 2005; 9: 209-215.

10 O'Donnell D, Forkert L, Webb K. Evaluation of bronchodilator responses in patients with "irreversible" emphysema. Eur Respir J 2001; 18: 914-920. 
11 Boschetto P, Miniati M, Miotto D, et al. Predominant emphysema phenotype in chronic obstructive pulmonary disease patients. Eur Respir J 2003; 21: 450-454.

12 Cerveri I, Pellegrino R, Dore R, et al. Mechanisms for isolated volume response to a bronchodilator in patients with COPD. J Appl Physiol 2000; 88: 1989-1995.

13 National Emphysema Treatment Trial Research Group. Rationale and design of the National Emphysema Treatment Trial: a prospective randomized trial of lung volume reduction surgery. Chest 1999; 116: 1750-1761.

14 American Thoracic Society. Standardization of Spirometry, 1994 Update. American Thoracic Society. Am J Respir Crit Care Med 1995; 152: 1107-1136.

15 Hoffman E, Reinhardt J, Sonka M, et al. Characterization of the interstitial lung diseases via density-based and texture-based analysis of computed tomography images of lung structure and function. Acad Radiol 2003; 10: 1104-1118.

16 Mishima M, Oku Y, Kawakami K, et al. Quantitative assessment of the spatial distribution of low attenuation areas on X-ray CT using texture analysis in patients with chronic pulmonary emphysema. Front Med Biol Eng 1997; 8: 19-34.

17 Pellegrino R, Viegi G, Brusasco V, et al. Interpretative strategies for lung function tests. Eur Respir J 2005; 26: 948-968.

18 National Collaborating Center for Chronic Conditions. Chronic obstructive pulmonary disease. National clinical guideline on management of chronic obstructive pulmonary disease in adults in primary and secondary care. Thorax 2004; 59: Suppl. 1, 1-232.

19 Rennard S, Anderson W, ZuWallack R, et al. Use of a long-acting inhaled $\beta_{2}$-adrenergic agonist, salmeterol xinafoate, in patients with chronic obstructive pulmonary disease. Am J Respir Crit Care Med 2001; 163: 1087-1092.

20 Dahl R, Greefhorst L, Nowak D, et al. Inhaled formoterol dry powder versus ipratropium bromide in chronic obstructive pulmonary disease. Am J Respir Crit Care Med 2001; 164: 778-784.

21 Mahler D, Wire P, Horstman D, et al. Effectiveness of fluticasone propionate and salmeterol combination delivered via the diskus device in the treatment of chronic obstructive pulmonary disease. Am J Respir Crit Care Med 2002; 166: 1084-1091.

22 Kim WJ, Silverman EK, Hoffman E, et al. CT metrics of airway disease and emphysema in severe COPD. Chest 2009; 136: 396-404.

23 Gross NJ. Outcome measurements in COPD: are we schizophrenic? Chest 2003; 123: 1325-1327.

24 Papi A, Romagnoli M, Baraldo S, et al. Partial reversibility of airflow limitation and increased exhaled $\mathrm{NO}$ and sputum eosinophilia in chronic obstructive pulmonary disease. Am J Respir Crit Care Med 2000; 162: 1773-1777.

25 Girard WM, Light RW. Should the FVC be considered in evaluating response to bronchodilator? Chest 1983; 84: 87-89.

26 Celli B, ZuWallack R, Wang S, et al. Improvement in resting inspiratory capacity and hyperinflation with tiotropium in COPD patients with increased static lung volumes. Chest 2003; 124: 17431748.
27 Newton M, O'Donnell D, Forkert L. Response of lung volumes to inhaled salbutamol in a large population of patients with severe hyperinflation. Chest 2002; 121: 1042-1050.

28 O'Donnell D, Lam M, Webb K. Measurement of symptoms, lung hyperinflation, and endurance during exercise in chronic obstructive pulmonary disease. Am J Respir Crit Care Med 1998; 158: 15571565.

29 O'Donnell D, Webb K, Bertley J, et al. Mechanisms of relief of exertional breathlessness following unilateral bullectomy and lung volume reduction surgery in emphysema. Chest 1996; 110: 18-27.

30 Martinez F, Montes de Oca M, Whyte R, et al. Lung volume reduction improves dyspnea, dynamic hyperinflation and respiratory muscle function. Am J Respir Crit Care Med 1997; 155: 19841990.

31 Kanner RE, Connett JE, Altose MD, et al. Gender difference in airway hyperresponsiveness in smokers with mild COPD. The Lung Health Study. Am J Respir Crit Care Med 1994; 150: 956-961.

32 Vestbo J, Soriano JB, Anderson JA, et al. Gender does not influence the response to the combination of salmeterol and fluticasone propionate in COPD. Respir Med 2004; 98: 1045-1050.

33 Martinez FJ, Curtis JL, Sciurba F, et al. Sex differences in severe pulmonary emphysema. Am J Respir Crit Care Med 2007; 176: 243-252.

34 Makita H, Nasuhara Y, Nagai K, et al. Characterisation of phenotypes based on severity of emphysema in chronic obstructive pulmonary disease. Thorax 2007; 62: 932-937.

35 Anthonisen N. Prognosis in chronic obstructive pulmonary disease: results from multicenter clinical trials. Am Rev Respir Dis 1989; 140: S95-S99.

36 Hansen E, Pharaneth K, Laursen L, et al. Reversible and irreversible airflow obstruction as predictor of overall mortality in asthma and chronic obstructive pulmonary disease. Am J Respir Crit Care Med 1999; 159: 1267-1271.

37 Anthonisen NR, Lindgren PG, Tashkin DP, et al. Bronchodilator response in the lung health study over 11 yrs. Eur Respir J 2005; 26: $45-51$.

38 Dowson L, Guest P, Stockley R. Longitudinal changes in physiologic, radiological, and health status measuremetns in $\alpha_{1}$ antitrypsin deficiency and factors associated with decline. Am J Respir Crit Care Med 2001; 164: 1805-1809.

39 Campbell AH, Barter CE, O'Connell JM, et al. Factors affecting the decline of ventilatory function in chronic bronchitis. Thorax 1985; 40: 741-748.

40 Kanner R. The relationship between airways responsiveness and chronic airflow limitation. Chest 1984; 86: 54-57.

41 Rodrigues-Carballeira M, Heredia J, Rue M, et al. The bronchodilator test with increasing doses of terbutaline in chronic obstructive pulmonary disease patients. Pulm Pharmacol Therapeut 2001; 14: 61-65.

42 Mahler D, Donohue J, Barbee R, et al. Efficacy of salmeterol xinafoate in the treatment of COPD. Chest 1999; 115: 957-965.

43 Miller M, Hankinson J, Brusasco V, et al. Standardisation of spirometry. Eur Respir J 2005; 26: 319-338. 